\title{
Diputaciones Provinciales y medios de transporte durante la Restauración. El caso de la Diputación Provincial de Guipúzcoa ${ }^{1}$
}

\author{
Carlos LARrinaga RodríGUEZ \\ Universidad de Granada \\ larrinag67@hotmail.com
}

Recibido: $12 / 03 / 2013$

Aceptado: 10/06/2013

\section{RESUMEN}

Tras la abolición de los Fueros y la puesta en marcha de los Conciertos Económicos, las diputaciones vascas se diferenciaron claramente de las diputaciones de régimen común por la capacidad fiscal que dichos Conciertos les otorgaban. Semejante competencia les permitió configurar un entramado tributario propio, al tiempo que les capacitó para hacer inversiones en aquellos rubros que consideraron más pertinentes para la provincia y para los intereses de esa burguesía ahora triunfante en el poder, como fue el caso de los medios de transporte. En este artículo tratamos de centrarnos en un estudio de caso, la Diputación Provincial de Guipúzcoa durante la Restauración.

Palabras clave: Concierto Económico, Diputación Provincial de Guipúzcoa, País Vasco, Restauración, modernización, puertos, ferrocarriles, carreteras.

\section{Local Public Administrations and Means of Transport During the Restoration. The Case of the Provincial Diputation of Guipúzcoa}

\begin{abstract}
After the abolition of the Fueros and the signing of the Economic Agreements -the so-called conciertos económicos-, Basque Diputaciones differed from the rest of their Spanish counterparts in their fiscal powers. Supported by the conciertos, they could set up their own taxation system and invest in those areas, such as transportation, they thought more relevant for the development of the Basque Provinces and the interests of the social group then in power: the bourgeoisie. In this article we focus on the case of the Diputación Provincial de Guipúzcoa in the years of the Restoration.
\end{abstract}

Key words: Economic Agreement, Provincial Diputation of Guipúzcoa, Basque Country, Restoration, Modernization, Ports, Railways, Roads.

Sumario: Introducción. 1. Las Diputaciones Provinciales en el contexto de la Restauración: diferencias entre las de régimen común y las concertadas. 2. Inversiones en la mejora del puerto de Pasajes: un caso diferenciado. 3. Inversiones en infraestructuras terrestres. 3.1. Ferrocarriles. 3.2. Carreteras. 4. Conclusiones.

1 Listado de abreviaturas: AGA: Archivo General de la Administración (Alcalá de Henares, Madrid) AGG-GAO: Archivo General de Guipúzcoa-Gipuzkoako Artxibo Orokorra (Tolosa, Guipúzcoa). 


\section{Introducción ${ }^{2}$}

La desaparición de los Fueros, al poco tiempo de la Segunda Guerra Carlista, supuso el nacimiento de una nueva institución en el País Vasco, la Diputación Provincial, una vez desaparecidas las antiguas Diputaciones Forales. Ante el trauma que supuso la supresión de los fueros, el Gobierno, tras negociar con los sectores más transigentes de los representantes de las tres provincias vascas, decidió pactar el régimen de Conciertos Económicos. Al mismo tiempo estaba previsto que se acordase también un Concierto Administrativo mediante el cual se delimitasen las funciones y competencias de las nuevas diputaciones. Finalmente esto no se hizo y las Diputaciones Provinciales Vascas trataron de asumir buena parte de las competencias que habían tenido sus antecesoras forales. Sin duda, la competencia de obras públicas fue una de ellas, optando por seguir apoyando la modernización de sus medios de transporte, en un momento decisivo de su historia, marcado por la industrialización. Si de forma muy general pueden definirse las infraestructuras como ese conjunto de equipamientos y estructuras que hacen posible del desarrollo económico de un área determinada, no es extraño que las Diputaciones Provinciales Vascas se esforzasen en la promoción de las mismas. Pues bien, a través del caso de Guipúzcoa, se pretende abordar esta cuestión dentro del marco de actuación del conjunto de las diputaciones vascas y en contraste con lo sucedido en las provincias de régimen común, cuyas inversiones en infraestructuras resultaron ser sensiblemente menores.

\section{Las Diputaciones Provinciales en el contexto de la Restauración: diferencias entre las de régimen común y las concertadas}

La administración española durante las décadas de la Restauración respondió a una idea centralizadora, caracterizada por el papel meramente administrativo de la Diputación y de la Comisión Provincial bajo el control político del gobernador civil. En realidad, este periodo supuso la consolidación de unos entes locales con varias décadas de historia, puesto que las diputaciones provinciales fueron contempladas ya en el articulado de la Constitución de 1812, aunque no fueron realmente organizadas hasta la ley de 1823. Con una clara influencia francesa ${ }^{3}$, a partir de ese momento se produjo el triunfo de un Estado centralista inspirado por el liberalismo doctrinario, contemplándose, no obstante, aunque sin éxito, algunas alternativas descentralizadoras de la mano, fundamentalmente, del federalismo ${ }^{4}$. Esta pretensión uniformizadora del Estado estuvo igualmente presente en la Constitución de 1876 y en las Leyes Provinciales

2 Una versión preliminar de este trabajo fue defendida en el XII Congreso de la Asociación de Historia Contemporánea (Granada, 12 al 15 de septiembre de 2012).

3 Para el análisis de la influencia del modelo centralista francés en España, véase MARCUELLO, Juan Ignacio: "La centralización administrativa en el ciclo de la Revolución Francesa", en José Luis GONZÁLEZ, Emilio LUQUE y Antonio VIZCAÍNO (eds.): In memoriam. Estudios dedicados a Antonio Ma Calero, Pozoblanco, Ayuntamiento de Pozoblanco y Diputación Provincial de Córdoba, 1998, pp. 35-50.

4 Véanse, entre otros, ARÓSTEGUI, Julio: "El Estado español contemporáneo: centralismo, inarticulación y nacionalismo", Historia Contemporánea, 17 (1998), pp. 31-57, y PÉREZ GARZÓN, J. Sisinio: "La nación, sujeto objeto del Estado liberal español”, Historia Contemporánea, 17 (1998), pp. 119-138. 
de 1876 y 1877 . Por lo que la ley de 21 de julio de 1876 , de la que finalmente se derivaría la abolición de los fueros vascos, debe ser entendida en este contexto del deseo de forjar una nueva administración dentro de un Estado liberal capaz de garantizar a todos los ciudadanos los mismos derechos y deberes, con una fiscalidad, un ejército $\mathrm{y}$ un mercado comunes, aunque, finalmente, en función del sistema de Conciertos Económicos, se abriría una brecha en dicho proceso de centralización ${ }^{5}$.

Atendiendo a este marco legislativo, lo primero que hay que señalar es que en la Constitución de 1876 la Diputación quedaba limitada a ser un órgano encargado de la administración de la provincia (art.82), con una serie de funciones y deberes básicos puramente administrativos (art.84). Por su parte, la Ley reformadora provincial de 16 de diciembre de 1876 mantuvo en vigor la ley provincial de 1870, si bien añadió algunas reformas de carácter restrictivo y centralizador ${ }^{6}$. En este sentido, cabe recordar que la ley de 1870 había respondido a los deseos de descentralización imperantes en los revolucionarios de 1868. De manera que dicha ley, acorde con la propia Constitución de 1869, implicaba una mayor autonomía para las provincias y las diputaciones (arts.46 y 47) ${ }^{7}$. Pero con las reformas introducidas en 1876 la Diputación Provincial pasó a estar sometida al gobernador, al que se le confirmó en la facultad de suspender dichas corporaciones provinciales o aplazar sus reuniones, además de poder presidir las sesiones con voz y voto. Con ello las diputaciones experimentaron un claro recorte en su autonomía y volvieron a convertirse, como en décadas anteriores, en correa de transmisión del centralismo del Gobierno ${ }^{8}$. Este fortalecimiento de la figura del gobernador como primera autoridad de la provincia se reforzó aún más en la Leyes Provinciales de 2 de octubre de 1877 y de 29 de agosto de 1882, la cual estuvo en vigor hasta 1925, en un contexto político-social marcado por el caciquismo9.

Siquiera someramente, conviene citar las competencias de las diputaciones provinciales durante estas décadas de la Restauración, a saber: competencias políticas, de tutela y control de los ayuntamientos, económico-administrativas y administrativas ${ }^{10}$. Para los objetivos de este artículo conviene detenernos en estas dos últimas. Englobada en las económico-administrativas estaba la Hacienda provincial. Pues bien, tras la revolución de 1868, el ministro de Hacienda Figuerola trató de impulsar la autonomía

5 DÍAZ HERNÁNDEZ, Onésimo: En los orígenes de la autonomía vasca: la situación politica y administrativa de la Diputación de Álava (1875-1900), Bilbao, IVAP, 1995, pp. 16-17. Sobre la construcción de la nueva autonomía vasca en la Restauración, véase también CASTELLS, Luis: "El nuevo marco administrativo y la autonomía (1876-1923)", en Luis CASTELLS y Arturo CAJAL (eds.): La autonomía vasca en la España contemporánea (1808-2008), Madrid, Marcial Pons, pp. 107-134.

6 DÍAZ HERNÁNDEZ, Onésimo: En los orígenes de la autonomía vasca..., pp. 17-18 y 30.

7 SANTANA MOLINA, Manuel: La Diputación Provincial en la España decimonónica, Madrid, MAP, 1989, pp. 145-151.

8 SANTANA MOLINA, Manuel: La Diputación Provincial..., pp. 160-162. El tratamiento del Gobernador en dicha ley en el art. $2^{\circ}$, disposición $7^{\mathrm{a}}$. Además, sobre la figura del Gobernador Civil en el siglo XIX, véase CAJAL, Arturo: El Gobernador Civil y el Estado centralizado del siglo XIX, Madrid, MAP, 1999.

9 GONZÁleZ CASANOVAS, J. A.: Las Diputaciones Provinciales en España. Historia politica de las Diputaciones desde 1812 hasta 1985, Madrid, Mancomunidad General de Diputaciones de régimen común, 1986, pp. 47-53; SANTANA MOLINA, Manuel: La Diputación Provincial..., pp. 164-173; DÍAZ HERNÁNDEZ, Onésimo: En los orígenes de la autonomía vasca..., pp. 29-30 y 68-73.

10 Un interesante análisis de las mismas en SANTANA MOLINA, Manuel: La Diputación Provincial..., pp. 238-273. 
financiera de las corporaciones provinciales respondiendo a ese programa de descentralización ya mencionado. Las diputaciones provinciales contarían desde entonces, 1870, con capacidad para aprobar sus propias cuentas y presupuestos, de manera que su financiación dejaría de costearse mediante los recargos sobre las contribuciones estatales. Es más, la tan odiada contribución sobre consumos desapareció ${ }^{11}$. Aunque la verdad es que semejante sistema impositivo fue un auténtico fracaso, repercutiendo no sólo en las haciendas locales, sino también en la estatal. La desaparición de la contribución de consumos hizo que la recaudación descendiese ostensiblemente, no compensada por las contribuciones directas, expuestas a continua ocultación y fraude ${ }^{12}$. Es por ello que en 1874 se tuvo que recurrir nuevamente al impuesto de consumos. Por lo que a las diputaciones se refiere, su reimplantación les repercutió a partir de 1882, cuando se estableció que el reparto que éstas tenían que hacer a los ayuntamientos se recaudaría no sólo de la parte proporcional que éstos pagasen por contribuciones directas, sino también por la misma proporción en los impuestos de consumos $^{13}$. Impuesto siempre muy controvertido por afectar al poder adquisitivo de los salarios, Navarro Reverter intentó suprimirlo en 1906, no siendo hasta 1911 cuando se decidió su abolición, estableciéndose entonces un periodo transitorio. Con todo, el peso del impuesto de consumos empezó a descender en la mayoría de las provincias desde finales del siglo XIX y principios del XX debido a su impopulari$\mathrm{dad}^{14}$. Por consiguiente, como estos ingresos no fueron suficientes, las corporaciones provinciales se vieron obligadas en numerosas ocasiones a recurrir a empréstitos ${ }^{15}$, muchas veces por los retrasos en el pago de la Hacienda central. Bajo este punto de vista, las haciendas provinciales fueron asimismo víctimas del déficit crónico que caracterizó a la Hacienda estatal durante el siglo XIX.

Lo cual, como es lógico, influyó negativamente en esas importantes competencias administrativas que tenían encomendadas: beneficencia, instrucción y obras públicas y fomento. La partida de gastos más importante del presupuesto de las diputaciones provinciales solía ser la de beneficencia, que se llevaba entre el 30 y el $40 \%$ del mismo, seguida en importancia de las partidas destinadas a obras públicas (carreteras y caminos vecinales), gastos de administración y servicios, enseñanza secundaria o cárceles ${ }^{16}$. Así se explica la diferente estructura de gasto de las provincias de régimen común respecto de las provincias vascas con régimen concertado. Su capacidad re-

11 MARTÍN NIÑO, Jesús: La Hacienda española y la revolución de 1868; Madrid, Instituto de Estudios Fiscales, 1972, pp. 302-315.

12 DEL MORAL RUIZ, Joaquín: Hacienda central y haciendas locales, Madrid, Instituto de Estudios de Administración Local, 1984, pp. 128 y ss. Una buena síntesis de las haciendas locales durante el siglo XIX y primeras décadas del XX, puede encontrarse en Francisco COMÍN: Historia de la Hacienda pública, II. España (1808-1995), Barcelona, Crítica, 1996, pp. 193-220.

13 SANTANA MOLINA, Manuel: La Diputación Provincial..., p. 259.

14 La comparativa entre Guipúzcoa y otras provincias españolas del peso del impuesto de consumos, en términos de tarifa por habitante, entre 1889-90 y 1907 puede verse en CASTELLS, Luis: Modernización y dinámica política en la sociedad guipuzcoana de la Restauración, 1876-1915, Madrid, Siglo XXI y Universidad del País Vasco, 1987, p. 451.

15 Hay que recordar que en numerosas ocasiones se invirtió en la construcción de carreteras provinciales y caminos vecinales y comarcales como forma de paliar el paro estacional (DEL MORAL RUIZ, Joaquín: Hacienda central y haciendas locales, p. 150).

16 DEL MORAL RUIZ, Joaquín: Hacienda central y haciendas locales, p. 146. 
caudatoria y sus atribuciones, como se verá más adelante, les permitieron, en función del sistema de Conciertos Económicos, llevar a cabo toda esta serie de inversiones en infraestructuras. Interesándonos aquí por las obras públicas, hay que señalar que las diputaciones de régimen común tenían competencia en la construcción de carreteras provinciales y comarcales y caminos vecinales, así como en su conservación, si bien a partir de 1877 la ejecución de estas atribuciones hubo de someterse a lo que se dispusiera en la normativa estatal ${ }^{17}$. Sólo las diputaciones vascas y navarra escaparon a esta realidad, gracias, precisamente, a ese mayor grado de autonomía del que disfrutaron durante todo este periodo ${ }^{18}$.

Para el caso de las provincias vascas que aquí nos ocupa, el cambio institucional más notable que permitió el acceso a esta autonomía fue la implantación del sistema de Conciertos Económicos ${ }^{19}$. En realidad, al término de la Segunda Guerra Carlista, la falta de entendimiento entre los representantes de las diputaciones vascas y el Gobierno derivó en la abolición del sistema foral vigente en los territorios vascos desde hacía siglos ${ }^{20}$. Con todo, el Gobierno de Cánovas promulgó el Real Decreto de 13 de noviembre de 1877 en el que se señalaba el cupo de contribución de inmuebles, cultivo y ganadería que durante el año económico de 1877-1878 habrían de pagar las Provincias Vascongadas y la forma de su exacción. Pero al carecer el Ministerio de Hacienda de datos seguros para establecer las sumas de la contribución, habida cuenta del carácter exento de dichas provincias durante tanto tiempo, se decidió fijar entonces un cupo asumible para cada una de las mismas. Esto abrió un nuevo periodo de negociaciones que culminó en el Real Decreto de 28 de febrero de 1878, inaugurando así el régimen de Conciertos Económicos ${ }^{21}$. En dicho decreto se establecía la forma en que cada una de las provincias vascas haría efectiva la obligación de contribuir económicamente al Estado. Así, cada provincia pagaría a éste el montante global previamente fijado, siendo las Diputaciones las encargadas de recaudar los impuestos y de establecer las contribuciones al efecto, con lo que cada Diputación se responsabilizaba de la recaudación y del pago al Estado del cupo correspondiente. De lo que se puede deducir que las Diputaciones siguieron manteniendo su autonomía fiscal. El convenio tendría una vigencia de ocho años, pero muy pronto las nuevas autoridades provinciales supieron ver las potencialidades del Concierto buscando sus sucesivas renovaciones.

17 SANTANA MOLINA, Manuel: La Diputación Provincial..., pp. 261-262 y 271.

18 Las características de esta autonomía en GÜENECHEA, José Nemesio: Ensayo de Derecho administrativo, Bilbao, Imprenta del Corazón de Jesús, 1915 (2ª ed.), t.I, p. 428.

19 Hay que advertir que Navarra siguió una evolución distinta a la de las provincias vascas, pese a contar igualmente con un Concierto Económico. Entre la abundante bibliografía existente, sobresale GARCÍA-SANZ MARCOTEGUI, Ángel: El fuerismo constitucional y la Diputación de Navarra (1841-1923), Pamplona, Gobierno de Navarra, 2011.

20 El debate en torno al carácter abolitorio o no de la ley de 21 de julio de 1876 es intenso y abundante en la historiografía vasca. Véanse, por ejemplo, CASTELLS, Luis: "La abolición de los Fueros vascos", Ayer, 52 (2003), pp. 117-150. CASTELLS, Luis y CAJAL, Arturo: "La negociación imposible (Cánovas y el fuerismo vasco en 1876)", Hispania, LXV/2, 220 (2005), pp. 601-642.

21 ALONSO OLEA, Eduardo J.: El Concierto Económico (1878-1937). Orígenes y formación de un Derecho histórico, Oñate, IVAP, 1995 y Continuidades y discontinuidades de la administración provincial en el País Vasco. 1839-1978, Bilbao, IVAP, 1999. 
Ese control fiscal que les otorgaba hizo que éstas aprovecharan dicha capacidad para el fomento de las actividades productivas. Hasta tal punto que incluso supuso un incentivo para la instalación de industrias frente a otras provincias españolas, donde la carga impositiva sobre estas actividades fue mayor ${ }^{22}$. En realidad, la nueva burguesía hegemónica, especialmente interesada en el fomento de la industria y del comercio, estableció un sistema impositivo favorable a sus intereses y actividades, de suerte que una de las consecuencias más trascendentes del nuevo régimen fue la baja presión contributiva sobre la industria y el comercio ${ }^{23}$. Por el contrario, el peso de los impuestos de consumos continuó siendo muy alto. Más aún, esa menor fiscalidad permitió asimismo una mayor acumulación de capital, incentivando así la capacidad de inversión ${ }^{24}$. Incluso, ese valor del cupo, al ser una cantidad fija establecida para una serie de años, en realidad iba disminuyendo progresivamente, si nos atenemos al crecimiento que al menos Vizcaya y Guipúzcoa experimentaron en esos años, por lo que esta disponibilidad de recursos propios se tradujo en una amplia libertad de iniciativa e inversión, lo que contribuyó a mejorar los medios de transporte, sobre todo, en las dos provincias marítimas. Aquí estribó, sin duda, una diferencia sustancial respecto de las provincias de régimen común, las cuales dependieron en gran medida de los presupuestos del Estado para mejorar sus respectivos sistemas de transporte y, a la postre, de su propia modernización.

En este sentido, nos interesa, aunque con brevedad, profundizar en el gasto público. Pues bien, para el periodo comprendido entre 1882 y 1913, en España aquél fue inferior al 10\% del PIB, mientras que en otros casos, como en Alemania, Francia o Italia, llegó a suponer una proporción más elevada, aunque manteniéndose por debajo del 15\%. El grueso de las partidas de gasto correspondió a los servicios generales y a la defensa y, sobre todo, a la deuda pública, la cual absorbió como promedio para todo el periodo el $37,7 \%$ de los gastos del Estado. La última guerra carlista y las guerras coloniales supusieron una auténtica sangría económica, incidiendo directamente en el endeudamiento del país. Un endeudamiento de tal calibre que hace que se le considere como una de las mayores causas de la debilidad del crecimiento y de la modernización de España. Así pues, con semejante estructura del gasto, no es de extrañar que las disponibilidades presupuestarias para infraestructuras y servicios económicos resultasen escasos ${ }^{25}$. De forma que sólo tras 1898 y la pérdida de las últimas

22 BARCENILLA, Miguel Ángel: La "pequeña Manchester". Origen y consolidación de un núcleo industrial guipuzcoano. Errenteria (1845-1905), San Sebastián, Diputación Foral de Guipúzcoa, 1999, p. 149.

23 Pese a que no contamos con un estudio sistemático sobre el perfil socio-económico y profesional de los diputados generales de la provincia y de los miembros de la Diputación Provincial para estas décadas, los datos que poseemos nos hablan del predominio de los intereses industriales y comerciales. A este respecto, véase CASTELLS, Luis: Modernización y dinámica politica....

24 ALONSO OLEA, Eduardo J. (1994): "Concierto Económico y fiscalidad privilegiada: el uso del “paraíso fiscal" vizcaíno. 1878-1937”, en Pablo MARTÍN ACEÑA y Montserrat GÁRATE (eds.): Economía y Empresa en el Norte de España, San Sebastián, Diputación Foral de Guipúzcoa, 1994, p. 265 y, para el caso guipuzcoano, CASTELLS, Luis: Modernización y dinámica política..., pp. 207-254.

25 MALUQUER DE MOTES, Jordi: “Crisis y recuperación económica en la Restauración (1882-1913)", en Francisco COMÍN; Mauro HERNÁNDEZ y Enrique LLOPIS (eds.): Historia económica de España, siglos $X-X X$, Barcelona, Crítica, 2002, pp. 257-259. Para constatar las semejanzas y diferencias con otros países europeos en lo que a la estructura del gasto se refiere, véase COMÍN, Francisco: Historia de la Hacienda pública, I. Europa, Barcelona, Crítica, 1996, pp. 113-120. 
colonias ultramarinas, se observa un incremento de las inversiones en obras públicas, educación, vivienda y sanidad, así como la introducción en España en determinados avances en materia laboral y de seguridad social (cuadro 1$)^{26}$.

Cuadro 1. Principales partidas de la estructura del gasto del Estado entre 1850 y 1923 (medias de los porcentajes con respecto al gasto total).

\begin{tabular}{|c|c|c|c|c|c|c|}
\hline Años & $\begin{array}{c}\text { Obligaciones de } \\
\text { la deuda }\end{array}$ & Defensa & $\begin{array}{c}\text { Servicios } \\
\text { generales }\end{array}$ & $\begin{array}{c}\text { Servicios } \\
\text { económicos* }\end{array}$ & Pensiones & Educación \\
\hline $1850-1854$ & 15 & 25 & 31 & 6 & 10 & 1 \\
$1855-1859$ & 21 & 22 & 26 & 9 & 8 & 1 \\
$1860-1864$ & 22 & 26 & 22 & 11 & 6 & 1 \\
$1865-1869$ & 38 & 18 & 20 & 8 & 6 & 1 \\
$1870-1874$ & 39 & 25 & 16 & 6 & 6 & 1 \\
$1875-1880$ & 28 & 27 & 19 & 8 & 6 & 1 \\
$1881-1886$ & 31 & 19 & 20 & 11 & 6 & 1 \\
$1887-1892$ & 35 & 20 & 13 & 10 & 7 & 2 \\
$1893-1898$ & 41 & 19 & 13 & 10 & 7 & 2 \\
$1899-1906$ & 43 & 19 & 12 & 9 & 8 & 3 \\
$1907-1914$ & 35 & 23 & 12 & 12 & 7 & 4 \\
$1915-1919$ & 36 & 23 & 10 & 11 & 5 & 3 \\
$1920-1923$ & 22 & 28 & 11 & 21 & 4 & 4 \\
\hline
\end{tabular}

* Recogen los gastos presupuestarios destinados a impulsar la economía del país, donde se insertarían las obras públicas, por ejemplo.

Fuente: COMÍN, Francisco: Historia de la Hacienda pública, II. España (1808-1995), Barcelona, Crítica, 1996, p. 40.

Teniendo en cuenta esta realidad, resulta interesante observar lo sucedido en materia de transporte en algunas diputaciones de régimen común. Por ejemplo, la Diputación de León gastó en la partida de obras obligatorias (mantenimiento de carreteras y caminos y del palacio provincial) el 1,55\% de su presupuesto en el año económico de $1888-1889$ y el $2,79 \%$ en 1897-1898, dedicando más de la mitad de sus gastos a la beneficencia, habida cuenta las condiciones económicas de la provincia ${ }^{27}$. Algo parecido se puede decir de la provincia de Ciudad Real, en la que, entre 1890 y 1924 , el porcentaje de gasto dedicado a carreteras fue en torno al $2 \%$, mientras que en beneficencia se alcanzó el $46 \%{ }^{28}$. La historia se repite en la Diputación de Soria para el último tercio del siglo XIX, donde la beneficencia copaba más de la mitad de los

26 COMÍN, Francisco: Historia de la Hacienda pública, II..., p. 42.

27 Para la distribución de los gastos en la provincia de León a finales del siglo XIX, véase CARANTOÑA, Francisco y PUENTE, Gustavo (dirs.): Historia de la Diputación de León, León, Instituto Leonés de Cultura, 1995, pp.178-179.

28 SÁNCHEZ SÁNCHEZ, Isidro (coord.): Historia de la Diputación Provincial de Ciudad Real (18351999), Ciudad Real, Diputación Provincial de Ciudad Real, 1999, p.54. 
gastos de su presupuesto, mientras que la instrucción pública y la promoción cultural se llevaba del orden del $20 \%$, lo que dejaba muy poco margen de maniobra ${ }^{29}$.

Siendo ésta la tónica general, la verdad es que podemos encontrar algunas excepciones. Sin duda, sobresale el caso de la provincia de Segovia, que desde 1878 contaba con un plan de carreteras provinciales. Aquí las malas condiciones económicas por las que atravesaban la Diputación y los pueblos de la provincia hicieron que la propuesta contemplara un empréstito de 4 millones de reales en acciones y obligaciones al interés del $8 \%$ anual, pagadero por trimestres vencidos y amortizables en el primer trimestre del año económico 1880-1881. Finalmente, la propuesta de endeudamiento no salió adelante, por lo que debieron obtener recursos mediante ajustes presupuestarios, tratando de no gravar excesivamente a los pueblos y descendiendo los gastos en sectores como la cultura o la beneficencia. De esta forma, y pese a las limitaciones, en 1892 estaban construidos 260 kilómetros de la red, atendidos y conservados en estado aceptable $^{30}$. Pese a todo, en 1894 se elaboró un nuevo plan de carreteras municipales, en virtud del cual la Diputación subvencionaría hasta un 33\% del presupuesto de la carretera proyectada a los ayuntamientos que tuviesen agotados sus recursos legales. El director de caminos provinciales se haría cargo del estudio técnico y los ayuntamientos sufragarían los gastos de dietas y desplazamientos del trabajo de campo. Todo lo cual nos da idea del importante esfuerzo económico realizado por la Diputación de Segovia en materia de carreteras entre 1888 y 1923, destinando una media anual para todo el periodo del $27,52 \%$ de su presupuesto, incluyendo en esa partida todo lo relacionado con este concepto (sueldos, material, etc.) ${ }^{31}$. Es posible que la extensión de su territorio, la proximidad a los núcleos de población tan importantes como Madrid y Valladolid y el hecho de que la línea del Norte finalmente discurriese por Ávila puedan explicar este afán inversor en carreteras.

Si tomamos por caso a una provincia industrializada como era Barcelona, sabemos que la hegemonía regionalista en la Diputación entre 1909 y 1913 repercutió de forma beneficiosa en la gestión administrativa de dicha corporación, inaugurándose un ciclo claramente expansivo, bien diferente al de estancamiento que se había dado en las etapas anteriores. Para 1910, por ejemplo, tanto los ingresos como los gastos alcanzaban los más de 8 millones de pesetas, siendo 1913 una excepción, ya que descendieron a 7,6. Pues bien, esos 8 millones contrastaban claramente con los 5 ó 6 millones de pesetas contabilizados en los años anteriores a 1910. Esta política expansiva adoptada por Prat de la Riva fue posible no sólo gracias a importantes empréstitos,

29 GARCÍA SEGURA, Ma Concepción: Historia de la Diputación Provincial de Soria. Siglo XIX. Años 1843-1902, Soria, Diputación Provincial de Soria, 2004, pp. 418 y ss.

30 En 1924 la red construida y conservada por la Diputación de Segovia era de 215 y 345 kilómetros, respectivamente, cifras que colocaban a esta corporación entre las primeras por la titularidad de la extensa red provincial y por el esfuerzo de su mantenimiento. Esfuerzo, no obstante, que progresivamente debió disminuir, ya que a la altura de 1924 el estado de las vías provinciales era malo e inadecuado para el tráfico automovilístico. El descenso en la inversión, la escasa remuneración de los peones camineros que veían en la agricultura mejores oportunidades y la carencia de maquinaria moderna e idónea parecen ser las causas de este deterioro.

31 ORDUÑA, Enrique: Evolución histórica de la Diputación Provincial de Segovia 1833-1990, Segovia, Diputación Provincial de Segovia, 1991, pp. 205-208. Las sumas específicas anuales y los porcentajes en el cuadro 1, p. 207. 
sino también al aumento de las entradas correspondientes al reparto entre los pueblos. Dicha política expansiva permitió a la corporación barcelonesa la conclusión del Plan de Caminos Vecinales, establecido en 1904-1905, e impulsar el nuevo Plan General de Caminos, cuyo objetivo principal era la superación de incomunicación de ciertas localidades de la provincia. De esta forma se pudieron recibir las obras definitivas de determinados caminos e impulsar la construcción de otras carreteras u obras públicas. Incluso, también la red ferroviaria en el ámbito de las comunicaciones secundarias experimentó un nuevo empuje gracias a las disposiciones provinciales referidas a las expropiaciones de terrenos. En definitiva, todo ello hace que las partidas de gasto vinculadas a reparación y conservación de carreteras, subvención a carreteras y caminos y construcción de carreteras provinciales aumentasen a principios de la década de $1910^{32}$. Esta tónica de importantes gastos en obras públicas en el sentido más amplio (carreteras, caminos y puentes, obras hidráulicas, teléfonos y, a partir de 1919-1920, ferrocarriles secundarios) debió mantenerse con posterioridad, si bien, cuando a principios de la década de 1920 los servicios y los ingresos de las diputaciones se traspasaron a la Mancomunidad de Cataluña, la situación cambió, ya que las diputaciones pasaron a convertirse en meras gestoras presupuestarias ${ }^{33}$.

De cuanto acabamos de señalar se puede deducir que la capacidad de recaudación de las diputaciones concertadas generó unas normativas fiscales sustancialmente distintas a las existentes en las diputaciones de régimen común. En concreto, estas últimas estaban constreñidas por la Ley provincial de 1882, que, en materia fiscal, les otorgaba unas facultades muy limitadas, al contrario de lo que sucedía en las provincias vascas gracias al sistema de Conciertos Económicos reconocido en dicha ley ${ }^{34}$. De ahí que las fuentes de ingresos difiriesen sensiblemente entre unas diputaciones y otras. Mientras en las de régimen común los ingresos provenían, sobre todo, de partidas de repartimientos y rentas ${ }^{35}$, en las concertadas el recurso que aportaba más fondos era el referido a los impuestos indirectos ${ }^{36}$. De esta forma, las diputaciones concertadas trataron de desgravar sectores productivos como la industria, la minería, el comercio o la navegación, para insistir, por el contrario, en la contribución

32 MARTÍN, Josep Lluís: "Dinàstics i regionalistes: 1898-1913”, en Borja de RIQUER (dir.): Història de la Diputació de Barcelona, Barcelona, Diputació de Barcelona, 1987, pp. 33-35. Para seguir con detalle la evolución de dichas partidas mencionadas, véase el cuadro 1 de la p. 34, aunque desgraciadamente no hay un desglose detallado de las diferentes partidas de gasto de la Diputación de Barcelona, como sí lo tenemos para el caso que nos ocupa.

33 UCELAY DA CAL, Enric: "La Diputació i la Mancomunitat: 1914-1923”, en Borja de RIQUER, (dir.): Història de la Diputació de Barcelona, Barcelona, Diputació de Barcelona, 1987, pp.166-167. Véase también GONZÁlEZ CASANOVAS, J. A.: Las Diputaciones Provinciales..., pp. 67-85.

34 GONZÁleZ CASANOVAS, J. A.: Las Diputaciones Provinciales..., pp. 103-104.

35 En 1868, 1870 y 1876 se dictaron leyes para la financiación de los gastos provinciales, recayendo siempre el grueso de la misma en el contingente de los ayuntamientos, es decir, en el repartimiento de la cuantía del déficit provincial entre los pueblos, de suerte que dicho reparto se hacía, como se ha dicho, en proporción a lo que cada pueblo pagase en concepto de las contribuciones directas y de consumos. Así, en 1905 , por ejemplo, el $72,8 \%$ de los ingresos de estas provincias procedían de los repartimientos, lo que da buena idea de este rubro en los ingresos de las diputaciones no concertadas (COMÍN, F.: Historia de la Hacienda pública, II..., pp. 208 y 219).

36 Para ver el peso de los impuesto de consumo en particular y de los impuesto indirectos en general sobre el total de los ingresos de la Diputación Provincial de Guipúzcoa, véase CASTELLS, Luis: Modernización y dinámica política..., p. 443, gráfico 26. 
indirecta. Esto es lo que posibilitó la expansión económica de finales del siglo XIX y principios del $\mathrm{XX}$, tratando de ponerse la propia institución provincial al servicio de estos intereses, jugando un papel determinante en la modernización de sus respectivos sistemas de transporte. A este respecto, no son de extrañar las importantes partidas dedicadas a obras públicas ${ }^{37}$, sobre todo, si tenemos en cuenta que estamos hablando de dos provincias que a lo largo del siglo XIX y principios del XX se fueron industrializando, de manera que a comienzos del siglo XX Guipúzcoa y Vizcaya, junto con Barcelona, eran las provincias más industrializadas de España ${ }^{38}$.

\section{Inversiones en la mejora del puerto de Pasajes: un caso diferenciado}

Tras el triunfo de la Revolución de 1868, el Gobierno apostó por la descentralización y por evitar que la Administración pública perjudicara la puesta en marcha de obras de interés general ahogando la iniciativa de los particulares. Pues bien, a este nuevo posicionamiento respondieron las Bases Generales para la nueva legislación de Obras Públicas del 14 de noviembre de ese mismo año, en función de las cuales las corporaciones locales y los particulares adquirieron cierta libertad de acción. Tal es así que, según el artículo 18, el Estado se comprometió a autorizar la concesión de obras que dependiesen de él a los particulares, empresas o corporaciones que lo solicitasen, sin poner dificultades. Aprovechándose de esta legislación, el 11 de diciembre se creó la Junta de Obras del Puerto de Barcelona, a las que muy pronto se sumaron las de Tarragona y Sevilla o Bilbao, por citar un puerto vasco ${ }^{39}$. En realidad, a partir de la de Barcelona fueron creándose unas cuantas en diferentes puertos españoles, siendo el proceso parecido en casi todos los casos. A instancias de una demanda local, impulsada por el Ayuntamiento, la Diputación o las organizaciones de comerciantes o por todos a la vez, se proponía una junta que debía estar presidida por el gobernador de la provincia y en la que debía estar representada buena parte de los intereses políticos y económicos de la ciudad portuaria, al tiempo que el Ministerio de Fomento mantenía el control y la titularidad de la dirección facultativa ${ }^{40}$.

Pues bien, frente a esta generalidad, cabe mencionar dos excepciones en el desarrollo de la gestión de estos organismos, Valencia y Pasajes. En Valencia la junta

\footnotetext{
37 Para analizar la estructura del gasto en Guipúzcoa y comprobar el peso de las obras públicas, véase CASTELLS, Luis: Modernización y dinámica política..., pp. 457-458. Asimismo, resulta interesante el índice de ingreso y/o gasto por habitante, como utiliza Anduaga para establecer comparaciones entre las diputaciones concertadas y las de Madrid y Barcelona. Véase ANDUAGA, Aitor: La cadena vasca, Barcelona, Ediciones del Serbal, 2010, p. 173.

38 VALDALISO, Jesús Ma: "La industrialización en el primer tercio del siglo XX y sus protagonistas", en José Luis de la GRANJA y Santiago de PABLO (coords.): Historia del País Vasco y Navarra en el siglo XX, Madrid, Biblioteca Nueva, 2002, p. 171.

39 PUERTA, Natividad de la: El puerto de Bilbao como reflejo del desarrollo industrial de Vizcaya (18571913), Bilbao, Autoridad Portuaria, 1994, pp. 106-109.

40 SÁNCHEZ PICÓN, Andrés y CUÉLLAR, Domingo: El Puerto de Almería (1805-2008). Una historia económica e institucional, Almería, Autoridad Portuaria de Almería, 2010, p. 14. Véase también ALEMANY, Joan: Los puertos españoles en el siglo XIX, Madrid, CEHOPU, 1991, pp. 105-109.
} 
inicial en 1880 estuvo promovida en exclusiva por la Diputación Provincial y fue reformada en 1902 para ser adaptada a las normas de los otros puertos. Pasajes, por su parte, mantuvo su autonomía hasta 1926, cuando se decidió su reversión al Estado $^{41}$. Dicho esto, nos vamos a centrar en la estrategia seguida por la Diputación de Guipúzcoa en el fomento del puerto de Pasajes, el más importante de la provincia durante todas estas décadas. Décadas que estuvieron marcadas por el proceso de industrialización de la provincia. En efecto, debido a las reducidas dimensiones de los muelles donostiarras, pronto los comerciantes y empresarios guipuzcoanos vieron en el cercano puerto de Pasajes amplias posibilidades para sus negocios, sobre todo, si tenemos en cuenta que el trazado de la Compañía del Norte tocaba dicho puerto, a pesar de encontrarse en esos años sesenta prácticamente anegado, debido a la falta de inversiones en las convulsas décadas del siglo XIX. El Estado, en virtud de un decreto del Ministerio de Fomento de 8 de febrero de 1870 y una ley de 12 de mayo de ese mismo año, cedió a la Diputación el puerto de Pasajes por un plazo de 90 años a cambio del pago de un canon anual y el abono de 3.800 escudos, que era lo que hasta entonces venía dando al Estado. La Diputación, por su parte, se comprometió a ejecutar las obras correspondientes para un tráfico de 100.000 toneladas, de modo que, si se excediese dicha cantidad, llevaría a cabo el segundo grupo de obras aprobado en 1869 y, de superarse las 500.000 toneladas, un tercer grupo ${ }^{42}$.

En estos primeros momentos, pues, la Diputación, todavía Foral, se erigió como la institución capaz de fomentar la recuperación del puerto de Pasajes en su deseo de fomentar la industria y el comercio guipuzcoanos, toda vez que desde el traslado de las aduanas en 1841 esta provincia había comenzado su proceso de industrialización. Consciente de las serias limitaciones de San Sebastián, había que recuperar una de las ensenadas más importantes del Cantábrico oriental con vistas a fomentar una infraestructura decisiva para su expansión económica. Pero la Diputación carecía de los medios económicos suficientes para afrontar esas primeras obras, valoradas entonces en unos 20 millones de reales ${ }^{43}$, por lo que se promovió la constitución de una "Sociedad de Fomento del puerto de Pasajes", fórmula bien distinta a la de las Juntas de Obras de Puertos, que ya hemos mencionado. La nueva empresa se encargaría de la explotación del puerto durante 44 años a contar desde el día de su constitución definitiva, para lo cual se fijó un capital de 2 millones de pesetas dividido en 4.000 acciones de 500 (una mitad permanente y la otra mitad amortizable) más otro millón de pesetas constituido por 2.000 obligaciones también de 500 pesetas. Los accionistas guipuzcoanos jugaron un papel predominante en la suscripción de este capital.

La Provincia seguiría manteniendo la propiedad de la concesión, entendiéndose directamente con el Gobierno en todo lo referente a ella. Además, garantizaría el interés del 5\% anual al capital de las acciones y del $6 \%$ al de las obligaciones ya emitidas. De esta forma la Provincia cubriría el déficit que pudiera darse al final de

41 SÁNCHEZ PICÓN, Andrés y CUÉLLAR, Domingo: El Puerto de Almería..., p. 14.

42 AGA, Obras Públicas, 24/709.

43 CASTELLS, Luis: Modernización y dinámica política..., p. 101. 
cada año entre el producto líquido de los rendimientos del puerto y la suma necesaria para pagar los intereses del capital desembolsado. Incluso, la Provincia asignaba para la amortización completa de las obligaciones, durante los 44 años mencionados, la cantidad de 10.000 pesetas anuales en tanto en cuanto la Sociedad no dispusiera de fondos necesarios para cubrir la amortización de las mismas ${ }^{44}$. Por lo tanto, parece innegable el importante papel desempeñado por la Diputación Foral de Guipúzcoa, que, garantizando los intereses de las acciones y de las obligaciones, trataba de allegar capital en un proyecto cuando menos arriesgado.

Las obras comenzaron, pero el estallido de la Segunda Guerra Carlista supuso un importante contratiempo, pues hubo que esperar al fin de la misma para que la Diputación autorizase nuevas emisiones de acciones y así retomar las obras. Gracias a los nuevos fondos los trabajos del primer grupo pudieron finalizarse en el primer semestre de 1881, al tiempo que el movimiento general del puerto pasó de 53.410 toneladas en 1879 a 144.201 en 1884 , año en que la Sociedad de Fomento optó por su disolución, toda vez que, alcanzadas ya las 100.000 toneladas de movimiento, era necesario emprender la segunda fase de las obras ${ }^{45}$. En estos momentos no fue posible conseguir los capitales locales suficientes para emprender la nueva fase. Fue entonces cuando la Diputación, empeñada en su tarea de fomentar dicha infraestructura para reactivar la economía de la provincia, decidió recurrir a nuevos inversores, para lo cual contactó con los empresarios franceses Daniel Ezpeleta y Ernesto Mourgues. Aquellos, para dar forma a la nueva sociedad, implicaron en la operación al conocido capitalista francés Eugenio Péreire, con lo que en 1884 nacía la "Sociedad general del Puerto de Pasajes". En todos los sentidos se abría una nueva etapa para el puerto de Pasajes, caracterizada por el predominio de gestores extranjeros y por la entrada de la Diputación en el Consejo de Administración de la Sociedad ${ }^{46}$, lo cual no fue un obstáculo para que pronto estallara el conflicto entre intereses muy contrapuestos.

Primero dentro de la Sociedad, entre los técnicos españoles y los franceses, respecto a las inversiones y a la acometida de las obras de infraestructura dentro del puerto, y después entre la misma Sociedad y la Diputación por la mala gestión y por la falta de inversiones y el incumplimiento de los plazos establecidos para la ejecución de las distintas obras de la segunda fase ${ }^{47}$. Prueba de ello es que las obras no concluyeron hasta 1906, con 17 años de retraso. Desde luego, para esa fecha se había producido un hecho fundamental desde la perspectiva que aquí nos interesa, cual fue la intervención de la Diputación Provincial de Guipúzcoa en la "Sociedad general del Puerto de Pasajes". En efecto, con vistas a superar las diferencias entre

\footnotetext{
44 Sendas copias de los Estatutos de la Sociedad de Fomento del Puerto de Pasages (San Sebastián, 1881), en AGG-GAO, JD IT 1830, 1 y DM, 36, 2.

45 LARRINAGA, Carlos: Actividad económica..., pp.140-147 y p. 122 para las cifras mencionadas.

46 La Diputación designaría dos administradores, el uno diputado provincial y el otro accionista.

47 Para un estudio más detallado del proceso de recuperación de Pasajes entre 1875 y 1902 y de las tirantes relaciones que se dieron entre la Diputación Provincial de Guipúzcoa y la Sociedad general del Puerto de Pasajes, véase LARRINAGA, Carlos: De la Diputación Foral a la Diputación Provincial de Guipúzcoa: autonomía administrativa y modernización económica durante la Restauración (1875-1902), San Sebastián, Fundación Kutxa, 2006, cap.4.
} 
la Sociedad y la Diputación, en 1901 se consiguió el acuerdo ${ }^{48}$, mediante el cual la Diputación se comprometía a suministrar los recursos necesarios con el fin de terminar las obras del segundo grupo. A cambio, la SGPP se obligaba a modificar sus estatutos, instituyendo un Consejo de Administración compuesto por nueve personas, de las cuales cinco serían elegidas por la Diputación y cuatro por los accionistas, lo que le daba el control sobre el Consejo. Era un intento por parte del ente provincial de velar por sus intereses y por los del desarrollo del puerto de Pasajes. Sólo así volvieron a retomarse las obras y se pudieron concluir en la fecha ya señalada.

Con los nuevos estatutos aprobados parecía llegado el momento de que los problemas que se habían suscitado en los años anteriores llegarían a su fin. Sin embargo, esto no fue así, ya que no tardaron en aflorar nuevamente las desavenencias, debido, precisamente, a las pocas inversiones en obras que se produjeron a partir de 1906. Volvieron a suscitarse nuevos conflictos entre la SGPP, la Diputación y los usuarios del puerto, cada vez más descontentos con su funcionamiento y con los servicios que ofrecía. Pero las cosas habían cambiado sensiblemente en el seno de la Sociedad, ya que ahora la Diputación nombraba a la mayoría de los miembros del Consejo, incluido al presidente. Por lo que desde esa fecha se observa una clara disminución en las inversiones (véase cuadro 2), de lo que cabe deducir que buena parte de responsabilidad pudo tenerla la propia Diputación. Precisamente, debido a esta falta de inversiones, la ley de 25 de noviembre de 1910 facultó al ministro de Fomento para concertar la reversión del puerto con la Diputación Provincial de Guipúzcoa y la "Sociedad general del Puerto de Pasajes". En tales circunstancias, es posible que Ramón Elósegui, el ingeniero director de la SGPP, optase por no realizar ninguna obra de envergadura ante semejante amenaza. De hecho, las críticas de los usuarios del puerto se cebaron con él, cuando, desde nuestro punto de vista, el Consejo de Administración, controlado por la Diputación, también debió tener alguna responsabilidad en esta actuación. Desde luego, no resulta fácil explicar cómo se llegó a esta situación y por qué las inversiones descendieron tan notablemente, pero es posible que el gran esfuerzo económico realizado hasta 1906 pudiese haber influido decisivamente en la falta de inversiones futuras, al menos en los primeros años. Posteriormente, con un clima ya favorable a la reversión, es posible que las autoridades portuarias decidieran no invertir más a la espera de que el puerto revirtiese al Estado.

\footnotetext{
48 AGG-GAO, JD IT 1830, 4: escritura de 25 de febrero de 1902 ante el notario Santiago Erro, así como Estatutos de la Sociedad General del Puerto de Pasajes con las modificaciones introducidas en junta general de accionistas de 30 de diciembre de 1901 y aprobadas por la Excma. Diputación provincial de Guipúzcoa en sesión de 3 de enero de 1902, San Sebastián, Imprenta de la Provincia, 1902. Para las negociaciones referentes a este acuerdo, véase AGG-GAO, JD IT 1830, 2.
} 
Cuadro 2. Capitales invertidos en la recuperación del puerto de Pasajes ${ }^{49}$ (en pesetas corrientes).

\begin{tabular}{|l|c|c|c|c|c|}
\hline & Hasta 1884 & $\begin{array}{c}\text { De 1884 a fin de } \\
1893\end{array}$ & $\begin{array}{c}\text { De fin de 1893 a } \\
\text { fin de 1901 }\end{array}$ & $\begin{array}{c}\text { De fin de 1901 a } \\
\text { fin de 1926 }\end{array}$ & Totales \\
\hline $\begin{array}{l}\text { Obras del puerto } \\
\begin{array}{l}\text { Obras y servicios } \\
\text { de explotación }\end{array}\end{array}$ & 2.185 .268 & 5.959 .219 & 374.944 & 1.078 .778 & 9.598 .569 \\
$\begin{array}{l}\text { Material y } \\
\text { mobiliario }\end{array}$ & 1.079 .639 & 1.083 .572 & 40.709 & 99.184 & 2.303 .104 \\
\hline Total & 112.318 & 277.617 & 17.998 & 354.491 & 762.424 \\
\hline
\end{tabular}

Fuente: Memoria que manifiesta el progreso y desarrollo del Puerto de Pasajes desde su reversión al Estado en enero de 1927 hasta diciembre de 1941, San Sebastián, 1942, p. 11.

En realidad, la idea de revertir el puerto de Pasajes al Estado empezó a ganar más fuerza aún hacia el año 1917, cuando, al estar próxima a alcanzarse la cifra de 500.000 toneladas de movimiento anual, la SGPP estaba obligada a comenzar las obras de la tercera fase, algo a lo que no estaba dispuesta ${ }^{50}$. Siendo esto así, el deterioro de las instalaciones portuarias cada vez era mayor, por lo que en los años veinte se aceleraron las conversaciones entre las tres partes implicadas (SGPP, Diputación y Ministerio de Fomento), aunque hubo que esperar al Real Decreto de 21 de mayo de 1926, el cual establecía el futuro régimen administrativo del puerto de Pasajes y disponía que la administración del mismo quedara en lo sucesivo confiada a una Junta de Obras. Así las cosas, a partir de 1927, pues, los muelles de Pasajes pasaron a estar gobernados por la Junta de Obras del Puerto, poniéndose fin a ese control que hasta entonces había tenido la Diputación Provincial de Guipúzcoa.

\section{Inversiones en infraestructuras terrestres}

\subsection{Ferrocarriles}

Si bien las primeras iniciativas ferroviarias en España tuvieron lugar a finales de la década de 1820, lo cierto es que hubo que esperar a la Real Orden de 31 de diciembre de 1844 para tener la primera disposición legal en materia de ferrocarriles. De forma que hasta entonces la acción del Estado había sido prácticamente inexistente. Con la nueva legislación las solicitudes de líneas aumentaron enormemente, pero el

49 Los datos aquí presentados fueron recogidos por Javier Marquina (primer ingeniero director de la Junta de Obras del Puerto de Pasajes) y, pese a algunas discrepancias, coinciden, para los años correspondientes, con el Dictamen del 15 de junio de 1914 de la Junta especial técnica. AGA, Obras Públicas, 24/1359, Resumen histórico, fol. 9r. La afirmación sobre Marquina en Memoria que manifiesta el progreso y desarrollo del Puerto de Pasajes desde su reversión al Estado en enero de 1927 hasta diciembre de 1941, San Sebastián, 1942 , p. 3

50 LUENGO, Félix: Crecimiento económico..., pp. 66-69. 
carácter especulativo de muchas de ellas hizo que los logros reales fuesen más bien $\operatorname{limitados}^{51}$. De ahí que hubiese que esperar a la Ley General de Ferrocarriles de 1855 y a las leyes bancarias de 1856 para que realmente se produjera el despegue del entramado ferroviario español. Un entramando en el que el País Vasco tuvo un papel destacado gracias a dos líneas, la Bilbao-Tudela (1863) y la Madrid-Irún (1864), que, en el contexto de su industrialización, le permitieron comunicar no sólo con Castilla y el valle del Ebro, sino también con el resto del continente europeo a través de Henda$\mathrm{ya}^{52}$. La puesta en funcionamiento de estas dos líneas coincidió con ese primer ciclo expansivo del ferrocarril en España, que finalizó a mediados de los años sesenta del XIX con la grave crisis financiera.

Cuadro 3. Formación Bruta de Capital Fijo en la construcción ferroviaria, 1855-1930 (millones de pesetas de 1990).

\begin{tabular}{|c|c|c|c|c|}
\hline & $\begin{array}{c}\text { Inversión } \\
\text { acumulada }\end{array}$ & $\begin{array}{c}\text { Inversión media } \\
\text { anual }\end{array}$ & $\begin{array}{c}\text { Kilómetros } \\
\text { construidos }\end{array}$ & $\begin{array}{c}\text { Kilómetros medios } \\
\text { anuales }\end{array}$ \\
\hline $1855-1870$ & 444.995 & 27.812 & 5.156 & 322,3 \\
$1871-1899$ & 923.253 & 30.775 & 7.681 & 256,0 \\
$1900-1905$ & 233.021 & 33.289 & 902 & 129,1 \\
$1906-1908$ & 102.813 & 34.271 & 529 & 176,0 \\
$1909-1918$ & 510.002 & 51.000 & 1.398 & 139,8 \\
$1919-1930$ & 663.381 & 55.282 & 1.314 & 101,0 \\
\hline
\end{tabular}

Fuente: CUBEL, Antonio y PALAFOX, Jordi: “Una perspectiva histórica del «stock» de capital ferroviario en España, en El «stock» de capital ferroviario en España y sus provincias: 1845-1997, Bilbao, Fundación BBV, 1999, p. 41.

Para este trabajo, sin embargo, y a la luz arrojada por los datos del cuadro 3, nos interesa más ese segundo ciclo inversor que se inició en 1871 y finalizó en 1899. Además de concluirse las conexiones de Madrid con Galicia y Portugal y de comenzarse a tender las líneas transversales de unión entre los trazados previamente finalizados, comenzaron a expandirse los ferrocarriles de vía estrecha, fórmula especialmente exitosa en la cornisa Cantábrica, donde estos ferrocarriles alcanzaron su mayor importancia. En este sentido, a partir de 1905 se detecta otro movimiento alcista en la inversión cuyas tasas más elevadas tuvieron lugar entre 1909 y 1912, con un predominio absoluto de la vía estrecha, gracias, precisamente, a los cambios legislativos de 1904 y 1907, en los que se promovía este tipo de líneas para las cuales se contempla-

51 Conviene recordar que en el decenio anterior a la ley de 1855, es decir, bajo la legislación de diciembre de 1844, sólo se habían abierto a la explotación 447 kilómetros de los 1.407 autorizados por las concesiones. COMÍN, Francisco y otros: 150 años de Historia de los Ferrocarriles Españoles, 2t, Madrid, Anaya y Fundación de los Ferrocarriles Españoles, 1998, tomo I, p. 64.

52 Para una visión general del impacto del ferrocarril en el desarrollo económico vasco, véase GONZÁLEZ PORTILLA, Manuel y otros: Ferrocarriles y desarrollo. Red y mercados en el País Vasco, 1856-1914, Bilbao, Universidad del País Vasco, 1995. 
ba la concesión por parte del sector público de una subvención equivalente al interés mínimo del $4 \%$ sobre el capital invertido ${ }^{53}$.

Precisamente, la legislación ferroviaria referida a la vía estrecha abrió la posibilidad de participar a los entes locales en el fomento de las iniciativas ferroviarias, algo que las diputaciones vascas no desaprovecharon. El ferrocarril era el mejor medio de articular el territorio y el mercado interior, por lo que, en pleno proceso de industrialización, vieron en él la infraestructura perfecta para tales objetivos ${ }^{54}$. Más aún si tenemos en cuenta que en la tradición foral los caminos eran una competencia de las Juntas Generales y Diputaciones, por lo que, desde el primer momento, el ferrocarril tuvo la consideración de un camino, aunque de hierro, y, por tanto, objeto de estudio de las diputaciones vascas ${ }^{55}$. Esta legislación renovó semejante interés por los caminos de hierro. Así, el 23 de noviembre de 1877 se aprobó una nueva ley de ferrocarriles, la denominada Ley General de Ferrocarriles y Tranvías, la cual venía a ser, en buena medida, una prolongación de la de 1855 , si bien en ella se introdujeron significativas modificaciones para subsanar los inconvenientes surgidos durante la primera fase de construcción de las líneas ferroviarias españolas. En realidad, la novedad más importante de la nueva ley estribó en detallar expresamente cuáles eran las líneas consideradas preferentes por parte del Estado para llevar a cabo su construcción, tratando de esta manera de estimular a la iniciativa privada con vistas a invertir en aquellas zonas peor dotadas de líneas férreas. Al mismo tiempo, abría la posibilidad de construir tranvías y ferrocarriles de vía estrecha, llamados "económicos", contemplando la participación y ayuda no sólo del Estado, sino también de los ayuntamientos y diputaciones. En estos casos estas líneas debían incluirse en los planes del Estado y su construcción tenía que ser autorizada por una ley especial. De esta forma se presentaba una posibilidad para la implicación de los entes locales en la construcción de líneas férreas y, desde luego, la Diputación Provincial de Guipúzcoa, al igual que las de Álava y Vizcaya, no la desaprovechó.

Estas líneas contribuyeron a articular mejor el territorio y a generar nuevos flujos de personas y de productos. De esta forma, y atendiendo a este marco legislativo comentado, en el caso que nos ocupa, tales trenes favorecieron una mayor integración del mercado guipuzcoano en particular y vasco en general, ya que la actividad constructiva a finales del siglo XIX y en las primeras décadas de la siguiente centuria fue muy notable. A decir verdad, el País Vasco fue uno de los territorios donde los ferrocarriles de vía estrecha alcanzaron más desarrollo ${ }^{56}$. En realidad, estas líneas se

53 CUBEL, Antonio y PALAFOX, Jordi: "Una perspectiva histórica del «stock» de capital ferroviario en España, en El «stock» de capital ferroviario en España y sus provincias: 1845-1997, Bilbao, Fundación BBV, 1999, pp. 44-45.

54 Según Herranz, la contribución de los ferrocarriles al crecimiento económico español entre 1850 y 1912 se situó entre el 11 y $13,3 \%$ del crecimiento total de la renta per cápita del país, sin incluir los efectos indirectos del ferrocarril, por lo que se hace difícil minimizar la importancia que tuvo el sistema ferroviario en el proceso del desarrollo económico español -y vasco, por supuesto- de esos años. HERRANZ, Alfonso: Infraestructuras y crecimiento económico en España (1850-1935), Madrid, Fundación de los Ferrocarriles Españoles, 2008, p. 174.

55 GONZÁLEZ PORTILLA, Manuel y otros: Ferrocarriles y desarrollo..., p. 85.

56 NOVO, Pedro A.: "Luces y sombras de una red ferroviaria en el País Vasco", en Miguel MUÑOZ (dir.): Historia de los Ferrocarriles de Vía Estrecha en España, 2t, Madrid, Fundación de los Ferrocarriles Españoles, 2005, pp. 151-240. 
concentraron en un número reducido de regiones, destacando claramente el norte de España, donde las redes tuvieron una mayor densidad, seguido de Mallorca, la región valenciana, Barcelona y Gerona en Cataluña y varios núcleos andaluces. Las demás líneas no pasaron de ser casos aislados en el contexto meramente regional en el que se localizaban ${ }^{57}$.

En líneas generales, parece cierto que sin las ayudas públicas resulta difícil defender que el ferrocarril hubiese superado en España la extensión derivada de un limitado número de vías de corto recorrido. Pero eso no obsta para afirmar que el principal esfuerzo en la inversión ferroviaria lo llevaron a cabo las compañías privadas. De hecho, se considera que la aportación pública mediante transferencias fue de aproximadamente la cuarta parte del total invertido ${ }^{58}$. Pero si a raíz de la ley de 1855 había sido el Estado el que había hecho tales transferencias, a partir de la ley de 1877 nuevos entes públicos, como las diputaciones, podrían desempeñar un papel clave en el fomento de las líneas ferroviarias. Centrándonos ya en el caso guipuzcoano, el 10 de noviembre de 1883 la Diputación Provincial estableció las bases generales para prestar apoyo material a los ferrocarriles que se construyeran dentro de los límites de la provincia o que atravesaran alguna zona de la misma. Evidentemente, era preciso que se considerase de utilidad el trazado de los mismos. En concreto, el documento presentaba cinco bases fijando las condiciones para poder obtener dichas ayudas. Primeramente era necesario el acompañar la instancia de la escritura pública de constitución de la sociedad, garantizando el aporte del 25\% del importe total del presupuesto referido a la obra y al material de explotación. Una vez examinado el proyecto para ver su utilidad o no para la provincia, la Diputación, en caso de decidir prestar su apoyo, suscribiría el 10\% de la suma total del coste de las obras y del material fijo y móvil que el presupuesto determinase que se habría de invertir en esta provincia, adquiriendo de esta forma todos los derechos que los estatutos de la sociedad establecieran para los accionistas. En tal supuesto, las entregas del capital suscrito se harían en cinco plazos y a partes iguales. Así mismo, la Diputación estaría representada en el Consejo de Administración de la empresa mediante un diputado tanto en el período de construcción como en el de explotación, cesando esta representación cuando se enajenase su paquete accionarial ${ }^{59}$.

Una vez establecidas estas bases, la Provincia parecía estar en condiciones de ayudar materialmente a las iniciativas ferroviarias que se presentasen. Y, en efecto, así fue, de manera que se puede hablar de una primera generación de vías férreas que se acogieron a tales bases y que contaron con el soporte material de la Diputación Provincial de Guipúzcoa, a saber: la de Durango (Vizcaya) a Zumárraga; la de Este1la (Navarra) a Durango ${ }^{60}$; y la de Elgóibar a San Sebastián. Con semejantes ayudas

57 Para una visión actualizada de los ferrocarriles de vía estrecha en España, véase MUÑOZ, Miguel (dir.): Historia de los Ferrocarriles de Vía Estrecha en España, 2 t. Madrid, Fundación de los Ferrocarriles Españoles, 2005.

58 CUBEL, Antonio y PALAFOX, Jordi: “Una perspectiva histórica del «stock»...”, pp. 28-29.

59 Registro de las sesiones celebradas por la Diputacion Provincial de Guipúzcoa durante el primer período semestral del año económico de 1883 á 1884, San Sebastián, Imprenta de la Provincia, 1884, pp. 71-72.

60 No hubo problema con el pago del primer plazo de la ayuda concedida, pero sí en los sucesivos por las modificaciones introducidas en el trazado y por la grave crisis por la que atravesó la Compañía del 
económicas la Diputación lo que pretendía era incentivar a las compañías ferroviarias para que construyesen cuantas más líneas mejor y, de esta forma, articular el territorio y unificar el mercado con el fin de favorecer a la industria y al comercio de la provincia. Unas buenas infraestructuras de transporte eran necesarias para una provincia con unas características orográficas tan particulares como las de Guipúzcoa. Y si para ello era preciso apelar a los representantes guipuzcoanos en las Cortes para que trabajasen a favor de las posibles líneas ferroviarias, la Diputación de Guipúzcoa no vaciló en recurrir a ellos ${ }^{61}$.

Precisamente, atendiendo a esta realidad tan compleja que suponía la concesión, construcción y explotación de líneas ferroviarias, cabe mencionar la aprobación en sesión del 16 de abril de 1891 de unas nuevas "Bases generales para el apoyo material que la Diputación acuerda conceder á los ferro-carriles que se construyan dentro de la Provincia ó atraviesen alguna zona de la misma" ${ }^{2}$. Ante las sucesivas peticiones de ayudas por parte de las compañías ferroviarias, y posiblemente teniendo muy presente los problemas sucedidos con el ferrocarril de Estella a Durango, parecía que el ente provincial quería aumentar las precauciones respecto de los auxilios económicos que prestaba. La idea era seguir manteniendo su apoyo, pero adaptando sus bases a la compleja realidad mencionada. De manera que, como se especificaba en las bases, se quería garantizar mejor los intereses de la Diputación, lo cual contribuiría no sólo a una mejor inversión de los fondos públicos, sino también a una mayor credibilidad de la institución. Además de estas precauciones, el ente provincial tampoco se comprometía a suscribir ese $10 \%$ mencionado en las bases de 1883 , de suerte que podría adquirir las acciones que considerase oportuno, entregando el capital suscrito en cinco plazos y sumas iguales. A cambio, la Diputación estaría representada en el Consejo de Administración de la compañía por un diputado elegido por ella, tanto en el periodo de construcción como de explotación.

En consecuencia, a partir de 1891, los proyectos ferroviarios que solicitasen el apoyo económico de la Diputación no tendrían más remedio que someterse al dictado de estas bases, entendiendo la Comisión de Fomento que de esta forma había mayores garantías de seguridad y acierto en el auxilio proporcionado a las compañías ferroviarias. Siendo esto así, la verdad es que las bases se aplicaron con bastante flexibilidad y generosidad, atendiendo a las necesidades y beneficios de la provincia, tal como se vio en el caso del ferrocarril entre San Sebastián y Pamplona, el cual, pese a no cumplir estrictamente el contenido de las bases, se benefició de una subvención en metálico de 125.000 pesetas $^{63}$. Con todo, la línea de Irún a Elizondo (Navarra) no

Ferrocarril Anglo-Vasco-Navarro, responsable de esa sección, derivando en la incautación de la línea por el Estado en 1897. Sobre esta línea ferroviaria, véase SANZ LEGARISTI, Pedro: El Ferrocarril AngloVasco y la Restauración en Álava (1880-1931), Vitoria, Diputación Foral de Álava, 1992. Para la gestión de la subvención con la Diputación guipuzcoana, véase LARRINAGA, Carlos: De la Diputación Foral a la Diputación Provincial de Guipúzcoa..., pp. 83-94.

61 AGG-GAO, JD IT 1535/8251.

62 Registro de las sesiones celebradas por la Diputación Provincial de Guipúzcoa durante el segundo período semestral del año económico de 1890 á 1891, San Sebastián, Imprenta de la Provincia, 1891, pp. 92-93.

63 Registro de las sesiones celebradas por la Excma. Diputación Provincial de Guipúzcoa durante el segundo periodo semestral del año 1913, San Sebastián, Imprenta de la Provincia, 1914, pp. 99-100. 
gozó de ayuda alguna por el incumplimiento evidente de las bases de 1891. Distinta fue, sin embargo, su actuación en la línea Estella-Vitoria por Los Mártires (Vergara), en la que se vieron implicadas las Diputaciones de Navarra, Álava y Guipúzcoa. En este caso, su actuación conjunta fue decisiva para impulsar la construcción de esta línea férrea, ya que los anticipos económicos estipulados sirvieron para reactivar el proyecto. Un proyecto que, posiblemente, si no hubiese sido por la actuación económica de las tres diputaciones, hubiese estado a punto de languidecer ${ }^{64}$.

Diferente y más decisiva fue aún la intervención de la Diputación Provincial de Guipúzcoa en el ferrocarril comprendido entre Zumárraga y Zumaya. Los sucesivos fracasos que se dieron en la construcción del camino de hierro del valle del Urola, cuyos orígenes datan de mediados de los ochenta del siglo XIX, animaron a la propia Diputación Provincial de Guipúzcoa a redoblar su interés por este asunto, haciéndose finalmente con la concesión y acometiendo directamente los gastos de la obra, inaugurándose la línea en $1926^{65}$. No era la primera vez que una Diputación vasca actuaba de esta manera, pudiendo recordar la construcción del ferrocarril de Triano por la Diputación de Vizcaya, por ejemplo.

Con el del Urola concluía la gran etapa de construcción de los ferrocarriles de vía estrecha en Guipúzcoa, un conjunto de líneas que, con el apoyo y el incentivo de la Diputación, había logrado una mejor articulación de la provincia y servir a los intereses económicos de la misma, completando a la línea del Norte y favoreciendo el intercambio de mercancías y de personas. Si tradicionalmente en Guipúzcoa las comunicaciones por su interior no habían sido fáciles, con el nuevo entramado ferroviario, complementado con las carreteras y caminos, este déficit consiguió paliarse progresivamente, en la medida en que ese stock de capital ferroviario aumentó a lo largo de los años de la Restauración ${ }^{66}$.

Pero llegados a este punto, cabe preguntarse si la actuación de la Diputación Provincial de Guipúzcoa fue excepcional y la respuesta es no, al menos respecto de las diputaciones de régimen concertado, ya que las de régimen común poco pudieron auxiliar a sus ferrocarriles provinciales. Ya se ha mencionado la participación de las Diputaciones de Álava y Navarra en el ferrocarril de Estella a Vitoria, por ejemplo. En el caso de Vizcaya, el tema de los auxilios provinciales se suscitó enseguida, en la medida en que la línea entre Bilbao y Durango fue la primera que se planteó en España tras la Segunda Guerra Carlista. Como en Guipúzcoa, también se fijaron unas bases para auxiliar a las compañías ferroviarias y fomentar así los trazados en suelo provincial ${ }^{67}$, con unos resultados enormemente positivos. Quizás por ello pueda de-

64 Véase SANZ LEGARISTI, Pedro: El Ferrocarril Anglo-Vasco...

65 ODRIOZOLA, Lourdes: "Aspectos económicos y sociales", en Ignacio ARTECHE, Lourdes ODRIOZOLA y Juanjo OLAIZOLA: El Ferrocarril del Urola, Azpeitia, Ayuntamiento de Azpeitia, 2002, pp. 105-145. Por su relevancia documental, véase también Registro de las sesiones celebradas por la Excma. Diputación Provincial de Guipúzcoa durante el primer periodo semestral del año 1920, San Sebastián, Imprenta de la Provincia, 1921, pp. 23-39.

66 Los datos provinciales pueden verse en CUCARELLA, Vicent: "El «stock» de capital ferroviario en España y sus provincias: 1845-1997", en El «stock» de capital ferroviario en España y sus provincias: 18451997, Bilbao, Fundación BBV, 1999, pp. 104-118y 135-149.

67 Para la cuestión de los auxilios materiales en Vizcaya, véase ALZOLA, Pablo: Monografía de los caminos y ferrocarriles de Vizcaya, Bilbao, Imprenta Provincial, 1898, pp. 149-168. 
cirse que tales actuaciones pueden contribuir a explicar que sólo en el País Vasco la densidad de la red ferroviaria llegó a ser mayor que la media continental, tal como se aprecia en el cuadro $4^{68}$.

Cuadro 4. Densidad de la red ferroviaria en las regiones españolas (1870-1930).

En kilómetros por cada $1.000 \mathrm{~km}^{2}$ de superficie.

\begin{tabular}{|l|r|r|r|r|r|r|r|r|r|}
\hline & \multicolumn{3}{|c|}{1870} & \multicolumn{3}{c|}{1900} & \multicolumn{3}{c|}{1930} \\
\hline & \multicolumn{1}{|c|}{$\begin{array}{l}\text { Vía } \\
\text { normal }\end{array}$} & $\begin{array}{c}\text { Vía } \\
\text { estrecha }\end{array}$ & Total & $\begin{array}{c}\text { Vía } \\
\text { normal }\end{array}$ & $\begin{array}{c}\text { Vía } \\
\text { estrecha }\end{array}$ & Total & $\begin{array}{c}\text { Vía } \\
\text { normal }\end{array}$ & $\begin{array}{c}\text { Vía } \\
\text { estrecha }\end{array}$ & Total \\
\hline Andalucía & 10,25 & 0,93 & 11,18 & 26,34 & 3,22 & 29,56 & 27,34 & 8,51 & 35,85 \\
Aragón & 7,65 & 0,00 & 7,65 & 14,74 & 1,49 & 16,23 & 19,31 & 5,72 & 25,03 \\
Asturias & 0,00 & 3,54 & 3,54 & 14,80 & 13,79 & 28,58 & 14,80 & 33,45 & 48,24 \\
Baleares & 0,00 & 0,00 & 0,00 & 0,00 & 23,80 & 23,80 & 0,00 & 44,10 & 44,10 \\
Canarias & 0,00 & 0,00 & 0,00 & 0,00 & 0,00 & 0,00 & 0,00 & 0,00 & 0,00 \\
Cantabria & 20,57 & 0,00 & 20,57 & 20,57 & 36,96 & 57,52 & 20,57 & 44,41 & 64,97 \\
Castilla-LM & 11,06 & 0,00 & 11,06 & 16,58 & 0,90 & 17,48 & 16,97 & 2,66 & 19,63 \\
Castilla-L & 9,52 & 0,00 & 9,52 & 22,34 & 3,19 & 25,53 & 26,02 & 5,93 & 31,95 \\
Cataluña & 19,60 & 0,14 & 19,75 & 34,82 & 7,21 & 42,03 & 37,14 & 13,19 & 50,32 \\
C. Val. & 15,42 & 1,53 & 16,95 & 29,43 & 12,22 & 42,65 & 31,73 & 18,51 & 50,25 \\
Extremadura & 5,44 & 0,00 & 5,44 & 18,68 & 0,96 & 19,64 & 18,68 & 0,96 & 19,64 \\
Galicia & 0,00 & 0,00 & 0,00 & 18,01 & 0,00 & 18,01 & 19,48 & 1,16 & 20,64 \\
La Rioja & 26,58 & 0,00 & 26,58 & 26,58 & 0,00 & 26,58 & 26,58 & 12,75 & 39,34 \\
Madrid & 26,19 & 0,00 & 26,19 & 38,30 & 15,73 & 54,03 & 38,30 & 27,22 & 65,52 \\
Murcia & 12,74 & 0,00 & 12,74 & 22,20 & 2,46 & 24,66 & 22,31 & 7,73 & 30,04 \\
Navarra & 21,02 & 0,00 & 21,02 & 21,02 & 1,81 & 22,83 & 21,02 & 19,15 & 40,18 \\
País Vasco & 35,27 & 0,00 & 35,27 & 36,95 & 48,26 & 85,20 & 36,95 & 75,40 & 112,34 \\
\hline España & 10,53 & 0,32 & 10,85 & 21,73 & 4,53 & 26,17 & 23,42 & 9,19 & 33,07 \\
\hline Europa & & & 23,98 & & & 57,78 & & & 71,51 \\
\hline
\end{tabular}

Fuente: HERRANZ, Alfonso: Infraestructuras y crecimiento..., p. 75, cuadro III-1.

\subsection{Carreteras}

Dentro de las infraestructuras terrestres las carreteras siguieron desempeñando un papel notable. De hecho, siendo verdad que los ferrocarriles fueron el medio de transporte por excelencia en el siglo XIX, el Estado liberal se interesó por una red de carreteras lo más extensa posible, que alcanzase hasta el último extremo de la geografía. Era la herramienta que el Estado liberal debía facilitar a sus ciudadanos para el desarrollo económico, al tiempo que le permitía el control y la articulación del territorio. Con la Restauración se mantuvo la clasificación de carreteras entre las de

\footnotetext{
68 Los datos desagregados para Guipúzcoa y el resto de provincias españolas, con vistas a hacer comparaciones, pueden encontrarse en El «stock» de capital ferroviario en España y sus provincias: 1845 1997, Bilbao, Fundación BBV, 1999. Por supuesto, a la hora de analizar esta densidad de la red ferroviaria, puede ser interesante apreciar también la densidad de población, que, en el caso de España, fue de 30,97 h/ $\mathrm{km}^{2}$ en 1860 y 39,44 en 1910, mientras que en Guipúzcoa, para esas mismas fechas, se pasó de 86,25 a 120,28, alcanzándose los 137,19 en 1920 (CASTELLS, Luis: Modernización y dinámica política..., pp. 167-168).
} 
primer, segundo y tercer orden, de acuerdo a su importancia y su ámbito geográfico: nacional, regional o provincial. Desde el punto de vista institucional, la Real Orden de 29 de diciembre de 1876 sentaba las bases para la nueva legislación en Obras Públicas, pretendiendo desmontar la legislación anterior, la del Sexenio, caracterizada por las políticas liberales y menor intervencionismo estatal. Respondiendo a este nuevo contexto, cabe citar la Ley de Carreteras de 4 de mayo de 1877 y el Plan General de Carreteras del 11 de julio de ese mismo año, aunque la inclusión al citado plan de un artículo adicional dejó las puertas abiertas a nuevas carreteras al mismo con la sola tramitación parlamentaria y sin contrastar debidamente su idoneidad. Lo que hizo que se colaran más de mil leyes que superaban los 40.000 kilómetros de carreteras, en su mayoría auspiciadas por caciques y políticos locales y sin que se llegaran a construir nunca. Al punto que una ley de 1911 suprimió dicho Plan General de Carreteras para evitar tales abusos ${ }^{69}$.

Ahora bien, en materia de carreteras, la Diputación Provincial de Guipúzcoa llegó a ejercer esta atribución a la manera en que lo había hecho su antecesora, la Diputación Foral ${ }^{70}$. En concreto, al amparo de la transición cuarta de la ley provincial de 29 de agosto de 1882 y del artículo 14 de la ley de presupuestos de 29 de junio de 1887, quedó legitimado el ejercicio indefinido de dicha competencia, de suerte que el nuevo marco legal imperante tras la ley de 21 de julio de 1876 no supuso una modificación sustancial de las atribuciones de la Diputación, que siguió haciendo frente al reto histórico de dotar a la provincia de una red viaria adaptada a las necesidades de una sociedad en plena transformación como consecuencia de los efectos de la industrialización y de la urbanización ${ }^{71}$. Lo cierto es que, concluida la guerra carlista, la Diputación trató de continuar con los planes proyectados y no ejecutados durante esos años bélicos. El gran momento de impulso de las carreteras en Guipúzcoa se produjo precisamente durante el último cuarto del siglo XIX (1879-1901), cuando se configuró un entramado viario ciertamente notable para el desarrollo económico de la provincia, sumando un total de algo menos de 84 kilómetros. La fórmula generalmente empleada consistió en que los ayuntamientos implicados ponían a disposición de la institución provincial los fondos necesarios para la construcción del camino o carretera en concreto a un interés anual del 5\% y con el compromiso de una amortización anual del 2\% del capital ${ }^{72}$. De esta forma la Diputación se implicó de manera evidente en la construcción de todos estos caminos, algo que también se puede apli-

69 CUÉLLAR, Domingo: Los transportes en el Sureste andaluz (1850-1950). Economía, empresas y territorio, Madrid, Fundación de los Ferrocarriles Españoles, 2003, pp. 94-95. El total de kilómetros de carreteras en España pasó de los 17.605 km en 1877 a los 61.767 en 1911, incluyendo estatales, provinciales y vecinales (HERRANZ, Alfonso: La dotación de infraestructuras en España (1844-1935), Madrid, Banco de España, 2004, pp.49-50, cuadro II-7.

70 Es cierto que en las negociaciones iniciales entre las Diputaciones vascas y el Gobierno para fijar el importe del cupo a pagar al Estado dentro del sistema de Conciertos Económicos se planteó el traspaso de las carreteras a la Administración central, aunque finalmente no se llevó a cabo para alivio de la Hacienda central, en esos momentos en serios apuros. Véase ALONSO OLEA, Eduardo J.: El Concierto Económico..., pp. 95-96.

71 RODRÍGUEZ RANZ, José Antonio y otros: Historia de las Vías de Comunicación en Gipuzkoa. 3/ 1833-1937, San Sebastián, Diputación Foral de Gipuzkoa, San Sebastián, 2003, pp.120-121.

72 RODRÍGUEZ RANZ, José Antonio y otros: Historia de las Vias de Comunicación..., pp. 147-149. 
car a Vizcaya, que consiguió tener la mayor densidad de red de carreteras de España a finales del siglo $\mathrm{XIX}^{73}$.

Más aún, entre 1898 y 1936 se construyeron en suelo guipuzcoano 82 caminos vecinales de primer orden, los cuales fueron configurando una notable red secundaria, cuya longitud en 1936 alcanzaba los 190 kilómetros. El objetivo final de esta actuación era el poner fin al aislamiento en que se hallaban hasta entonces los pequeños núcleos de población, así como el facilitar el acceso a las estaciones de las diversas compañías ferroviarias que operaban en la provincia. Pero no sólo eso, ya que la Diputación se encargó asimismo de la mejora y mantenimiento de las vías de comunicación existentes, algo que, por las características orográficas del territorio y por su propio clima, implicó gastos muy cuantiosos. Como en materia de ferrocarriles, también en carreteras, tanto Guipúzcoa en particular como el País Vasco en general sobresalieron respecto de las demás regiones de España.

Cuadro 5. Densidad de la red de carreteras en las regiones españolas (1870-1930). En kilómetros por cada $1.000 \mathrm{~km}^{2}$ de superficie.

\begin{tabular}{|l|r|r|r|r|r|r|r|r|r|}
\hline & \multicolumn{3}{|c|}{1870} & \multicolumn{1}{c|}{1900} & \multicolumn{3}{c|}{1930} \\
\hline & $\begin{array}{c}\text { Red del } \\
\text { Estado }\end{array}$ & $\begin{array}{c}\text { Redes } \\
\text { provinciales } \\
\text { y vecinales }\end{array}$ & Total & $\begin{array}{c}\text { Red del } \\
\text { Estado }\end{array}$ & $\begin{array}{c}\text { Redes } \\
\text { provinciales } \\
\text { y vecinales }\end{array}$ & $\begin{array}{r}\text { Total } \\
\text { Red del } \\
\text { Estado }\end{array}$ & $\begin{array}{c}\text { Redes } \\
\text { provinciales } \\
\text { y vecinales }\end{array}$ & Total \\
\hline Andalucía & 23,59 & 5,43 & 29,02 & 61,05 & 8,97 & 70,02 & 112,65 & 40,92 & 153,57 \\
Aragón & 21,98 & 1,68 & 23,66 & 66,36 & 1,92 & 68,27 & 122,44 & 20,00 & 142,44 \\
Asturias & 42,98 & 24,56 & 67,55 & 120,86 & 14,68 & 135,55 & 197,95 & 70,78 & 268,72 \\
Baleares & 34,71 & 90,69 & 125,40 & 69,87 & 90,69 & 160,56 & 211,00 & 72,73 & 283,72 \\
Canarias & 12,91 & 5,82 & 18,73 & 37,25 & 0,00 & 37,25 & 120,66 & 17,29 & 137,94 \\
Cantabria & 83,26 & 4,36 & 87,63 & 166,45 & 22,55 & 189,00 & 257,89 & 80,04 & 337,94 \\
Castilla-LM & 22,63 & 4,78 & 27,41 & 66,41 & 2,96 & 69,37 & 122,40 & 26,73 & 149,13 \\
Castilla-L & 38,47 & 6,77 & 45,24 & 77,71 & 21,08 & 98,79 & 135,71 & 64,61 & 200,32 \\
Cataluña & 50,47 & 15,99 & 56,56 & 85,92 & 35,67 & 121,59 & 158,02 & 81,87 & 239,89 \\
C. Val. & 35,01 & 19,29 & 54,30 & 80,95 & 24,34 & 105,30 & 148,67 & 80,52 & 229,89 \\
Extremadura & 23,29 & 0,22 & 23,52 & 51,19 & 0,90 & 52,09 & 79,33 & 30,76 & 110,10 \\
Galicia & 58,35 & 2,41 & 60,73 & 97,18 & 21,38 & 118,57 & 179,66 & 71,69 & 251,35 \\
La Rioja & 67,73 & 23,63 & 91,36 & 151,96 & 13,52 & 165,49 & 189,36 & 57,23 & 246,60 \\
Madrid & 68,21 & 12,64 & 80,85 & 127,90 & 61,42 & 189,32 & 183,28 & 120,76 & 304,05 \\
Murcia & 26,73 & 2,48 & 29,21 & 65,98 & 1,21 & 67,19 & 130,15 & 71,02 & 201,17 \\
Navarra & 0,00 & 102,43 & 102,43 & 0,00 & 169,88 & 169,88 & 44,75 & 192,28 & 237,04 \\
País Vasco & 35,26 & 202,35 & 237,61 & 0,03 & 267,82 & 267,85 & 94,10 & 292,75 & 386,85 \\
\hline España & 31,55 & 12,19 & 43,75 & 71,37 & 20,71 & 92,08 & 130,14 & 56,34 & 186,48 \\
\hline Europa & & & 350,99 & & & 412,90 & & & 489,09 \\
\hline
\end{tabular}

Fuente: HERRANZ, Alfonso: Infraestructuras y crecimiento..., p. 76, cuadro III-2.

73 ALZOLA, Pablo: Monografia de los caminos..., p. 91. 


\section{Conclusiones}

A tenor de los visto en este trabajo, podemos extraer las siguientes conclusiones. En primer lugar cabe hablar de una cierta continuidad en lo que a competencias se refiere entre las Diputaciones Forales vascas y las Diputaciones Provinciales surgidas a lo largo de 1877. Ante la falta de un Concierto Administrativo que delimitase bien sus competencias, las nuevas corporaciones provinciales trataron de seguir con las atribuciones de los extintos entes forales. En segundo lugar, el sistema de Conciertos Económicos no sólo sirvió para apaciguar los ánimos tras la desaparición de los fueros, sino que constituyó la base de una nueva autonomía provincial que devino en un marco institucional propicio para la modernización económica tanto de Guipúzcoa como del resto de las provincias vascas. Tal vez podría pensarse que esta descentralización de la que disfrutaron las provincias concertadas supuso un factor favorable para su modernización económica. En tercer lugar, y gracias a ese sistema, hay que hablar de la diferente estructura de gasto que caracterizó a las Diputaciones concertadas respecto de las Diputaciones de régimen común, las cuales se vieron constreñidas por las sucesivas leyes provinciales en sus actuaciones. La distinta estructura de ingresos en uno y otro caso determinó, pues, las inversiones. Así, cuando las Diputaciones de régimen común se vieron obligadas a invertir importantes sumas en beneficencia e instrucción, poco pudieron hacer para mejorar sus infraestructuras. Por el contrario, las Diputaciones concertadas, caracterizadas por su capacidad fiscal, gastaron importantes sumas de dinero en obras públicas, en especial en medios de transporte. Sus propias características orográficas, siendo el caso de Guipúzcoa paradigmático, les indujo a tales inversiones.

En cuarto lugar, esa burguesía comercial e industrial que se había ido consolidando desde el siglo XVIII estableció un sistema fiscal favorable a sus intereses, gravando los consumos y canalizando los recursos conseguidos en favorecer unos medios de transporte necesarios para el desarrollo económico de la provincia. Teniendo en cuenta las difíciles condiciones físicas de Guipúzcoa, en todos estos años la Diputación trató de hacer inversiones para atenuar estas dificultades. Sólo teniendo unos medios de comunicación modernos se podría romper con dichos obstáculos naturales e integrar a la provincia dentro del mercado español y europeo. De ahí que no dudara en continuar con las inversiones que la desaparecida Diputación Foral llevaba haciendo desde hacía tiempo. No son extraños, por tanto, los elevados porcentajes que dedicó a Obras Públicas (cerca del $20 \%{ }^{74}$ ) durante estos decenios. Semejante peso de los intereses industriales y comerciales tuvo, sin duda, su reflejo en las inversiones llevadas a cabo por la Diputación en este terreno. Por último, y enlazando con lo anterior, a las iniciativas empresariales particulares pronto se sumó la intervención de la Diputación Provincial con actuaciones que buscaban incentivar la actividad económica. Su papel en la recuperación del puerto de Pasajes o los auxilios económicos establecidos para el fomento de la puesta en marcha de diferentes líneas ferroviarias en la provincia así lo ponen de manifiesto. Se trataba, en definitiva, de atraer capital privado inversor mediante diferentes tipos de incentivos.

\footnotetext{
${ }^{74}$ CASTELLS, Luis: Modernización y dinámica política..., pp. 457-458.
} 